\section{The genome rush of 1996}

Flush with possibility, opportunity, and cash, the real work of the genome enterprise is just beginning. In this issue, we have mapped (quite literally, on a pullout) the current status of the genome boom, showing the commercial relationships between small companies specialized in collecting and organizing genetic information and larger companies whose main strengths lie in developing drugs.

Taken collectively, the great contribution of genomics companies to date has been to amass enough money from investors ( $\$ 535$ million; E. Silverman, Genomics: An Investor's Guide, Punk, Ziegel \& Knoell, New York, 1996) to acquire the technical resources necessary to demonstrate just how it is that genomic information will be able to drive drug development forward. Senior managers at pharmaceutical companies would never have sanctioned this kind of in-house investment, nor would they sanction it now, but the advent of genomics companies has given them several good R\&D options at a cost of only a few hundreds of millions of dollars, a tiny fraction of their average annual R\&D budgets ( $\$ 15.8$ billion; PhRMA annual survey, Washington, DC, 1996).

The relationships that pharmaceutical and genomics companies have forged over the past few years indicate that the baton of drug development based on genomic studies will pass, by and large, to pharmaceutical companies. They will apply the disciplines of industrial development, focusing resources on areas of potential commercial value while ignoring others completely. Genomics companies will make money by trafficking in genetic information and technology based on large-scale sequencing, positional cloning, and so on. But what of the pharmaceutical companies? How will they justify their investment while waiting for the drugs that they are banking on to gush forth from the genomic pipeline? Prognostic and diagnostic genetic tests will be the first and easiest way. Then drugs, many and potent, protein and small molecule, along with gene therapy and antisense therapy, are what they hope the future has in store.

Despite the current rush of enthusiasm for all things genomic, many significant technical and organizational problems remain to be addressed in the effort to link genes to function and then to drug development. Among them are the "simple" problems of finishing and validating the actual sequences, integrating and automating DNA/cDNA cloning, subcloning, and physical mapping, organizing information curation and analysis, and developing appropriate animal models, screens, and trials. But how genome mines ultimately play out will also depend on economic and social forces that lie beyond these straightforward complexities.

As has been discussed previously by Stanley Crooke and others in these pages, new drug discovery technologies will have a major economic impact on what comes before and what goes after them in the drug development chain. Today's drug discoverers pinpoint molecular targets that are often members of multigene families supporting many biological processes. Abnormal behavior on the part of any member of one of these families can result in many different disease manifestations that can then be categorized. In contrast, rational drug use focuses on patients with symptoms that are subsequently assigned to disease categories. Business strategies have been developed around these symptom classifications, for example, cardiovascular disease or cancer. In effect, then, the biopharmaceutical industry's business is organized around one classification of disease, while its research is organized around quite a different one, based on the mechanisms underlying disease processes. If the industry's research activities are successful, they will make some of the ways its business is organized obsolete.

In marshaling the forces of genomic technology, there will be many social issues to contend with. What will be the goals of scientifically driven genetic medicine - to extend life indefinitely and to bring everyone to perfect health? What will it mean for a society if its citizens, or at least some of them, can live to be 150 ? How will we deal with inevitable issues concerning medical resource allocation? Will too much energy and emphasis be placed on genetic solutions to medical and health care problems, to the exclusion of other, perhaps less expensive, therapies or social solutions? Will we be able to make more immediate and pressing social policy decisions dealing with issues of genetic screening and job and health-care discrimination, autonomy, and privacy, in anticipation of the problems they will engender? Or will we wait, as we have so often in the past, until crises occur?

And then there will be unexpected complications and connections, impossible to predict, much less manage. To give one example, Ed Tenner reminds us in his book, Why Things Bite Back: Technology and the Revenge of Unintended Consequences, that the genetic mechanisms responsible for early reproductive success may have a long-term costresearch suggests that prostate cancer is a consequence of the genes that promote seminal fluid production and thus greater fertility earlier in life. Such interconnectivities will continue to be established. So where does intervention lie?

As societies at the end of the 19th century contended with the social transformations brought about by electricity and chemistry and mechanical technologies, we are now at the beginning of a genetic transformation. As genetic research moves out of the domain of basic research and into that of the applied, addressing the issues mentioned above will require flexibility and care and time and money. There will be scientific jobs, to do the work of assigning patterns of meaning to the sequence data now being gathered, but there will also be responsibilities for monitoring the progress that lies ahead. It will be important to remember, for example, that not all medical problems require a gene therapy or gene drug solution. Gene sequences by themselves are value neutral, but once attempts are made to use them, the urge to fit the data to our own agendas, hypotheses, and social theories will need to be held in check.

Appearing before a congressional committee about to fund the Human Genome Project, James Watson said, "We used to think our fate was in the stars; now we know in large measure, our fate is on our genes." But finally our fate lies, neither in the stars nor in our genes, but in our brains and how we use them to sort and process the information we are so busily gathering. With an eye to the market, to government health-care policies, and to competing technological approaches, pharmaceutical executives will decide what is plausible and what is potentially profitable with respect to genomics. Ideas about what is right and what is good and what is worth doing will need to come from the individuals who make up a variety of scientific, cultural, economic, and governmental institutions. Genome paradise or a genome wasteland, it will be ours to make. 